\title{
THE PROGRESS OF THE EUROPEAN BISON
}

\author{
By Dr. JAN Ź'ABIŃskI
}

The number of species in danger of disappearing from the earth increases every year. Nevertheless, even the brief story of the two species belonging to the genus of bison cannot fail to evoke a striking picture of the two different ways in which man proceeds with his destruction of the animal world. One of these ways is obvious : the other may be almost imperceptible.

The extirpation of 15 millions of American bison by bullets over a period of twelve years at the end of the nineteenth century is the example of the obvious form of destruction. The lot of the European bison, though equally tragic in its effect, does not appeal with the same force to the popular sentiment, because in its case there has been no spectacular bloodshed and the process of extirpation has stretched over the period. of twelve centuries instead of twelve years. Nevertheless the history of this species is full of facts which are not only of great interest to the man connected with the protection of nature, but can also supply valuable observations to both the ecologist and the sociologist.

Unlike the American bison which lives on the prairies, the European bison is, and has always been, a forest animal. It inhabited the damp taiga forests of the moderate European climate, never reaching the southern peninsulas or the northern regions of Scandinavia. But from the beginning of the sixth or seventh eentury, the mid-European forests slowly divindled, starting from the West. This process was accompanied by the gradual disappearance of the bison, in spite of the fact that sovereign princes in the affected territories introduced most severe laws, including the death penalty, against those who killed their royal animals. These legislative measures must not, however, be thought of as forerunners of present day nature conservation. The rulers protected the bison merely to safeguard their own hunting pleasures.

Ten centuries later the remains of the virgin European forests, the so-called Puszcza Bialowieska, covered only some thousands of square kilometers and contained the last few hundreds of surviving bison-300 to 500, according to various sources. After the partition of Poland these forests became the private hunting grounds of the Tsar.

Although at that time, i.c., the end of the eighteenth and the beginning of the nineteenth century, the administration was able 


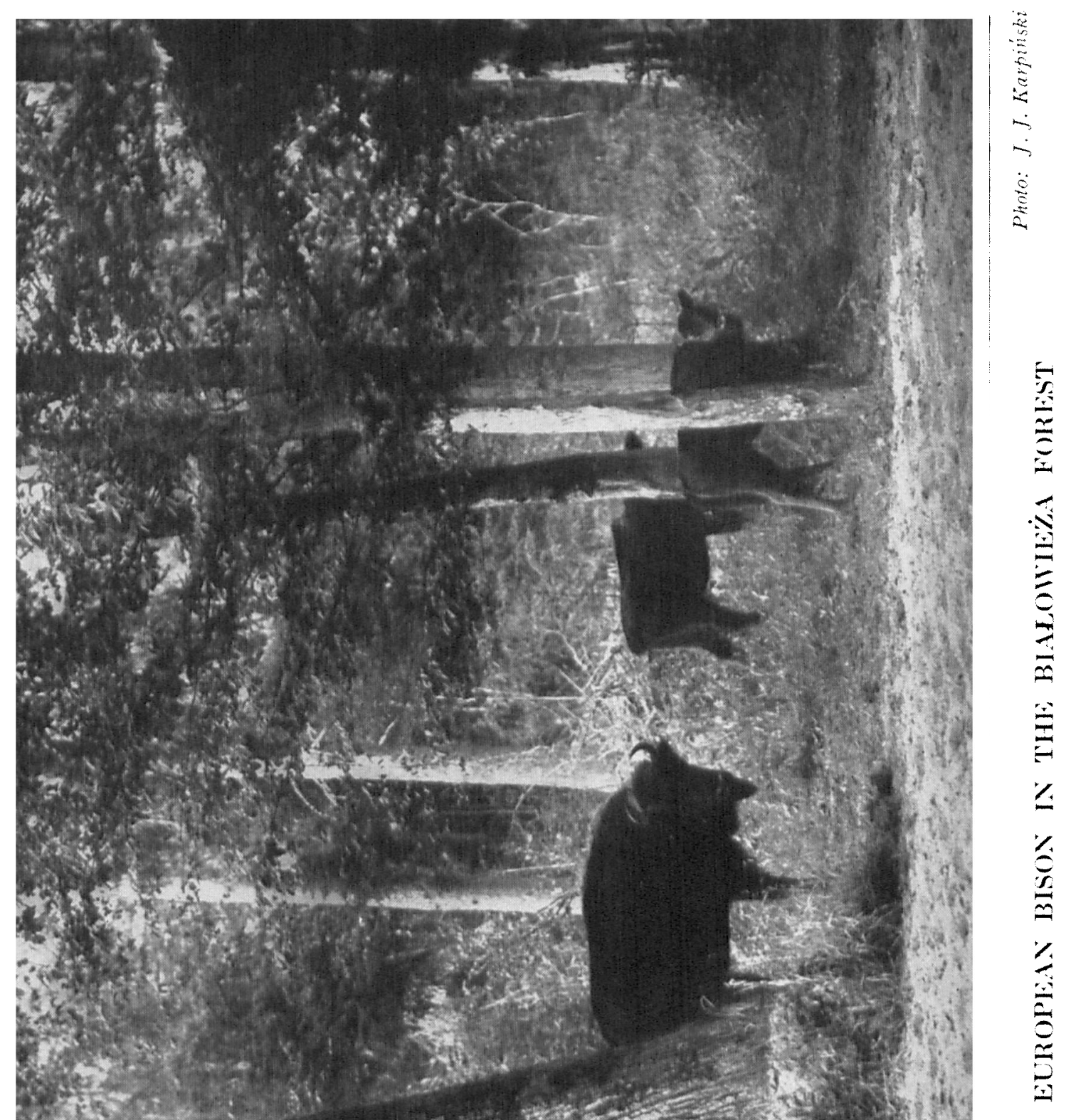


to secure protection against the most obvious forms of poaching, and, although during the whole nineteenth century Court hunting parties were very rare, the growth of the bison population was very slight in spite of winter feeding. According to the 1913-14 census, the number of animals was 717 , which meant that during 1.00 years the population had only doubled. Contemporary Russian scientists wrote about the degeneration and the loss of vital powers of this species, suggesting that these were the main reasons for its decline.

During World War I the ruthless German military economy reduced the number of bison in Białowieża to 200 in the course of three years. But that was not yet the end. After 1919-20, when the German armies retreating from the eastern front passed through Białowieza, the forests remained for some time in the hands of the Lithuanians and were twice the scene of bitter fighting between the Polish and Bolshevist armies. When the war was over not a single bison was alive in the forest of Białowieza. About the same time, the last European bison in the Caucasus were killed, for, as it was revealed in the middle of the nineteenth century, several hundred had survived on the northern slopes of these mountains. By then the only living representatives of the European bison in the world were the animals in the Zoos or belonging to private owners.

During the international meeting on the protection of nature, held in Paris in 1923, Mr. Jan Sztolcman, a Polish naturalist and traveller, proposed the organization of the International Society for the Protection of the European Bison. The new institution regarded as its first and most important task the verification of the surviving animals of the species, as there had been numerous cases of cross-breeding with the American bison.

The first issue of the Pedigree Book, edited by $A$. von der Groeben, appeared in 1932. The next two issues were published in 1935 and 1937. The editor was Dr. Erna Mohr. After that time the story of the struggle for survival of the Bison bonasus is best illustrated by the numbers quoted in the Pedigree Books which are published periodically. 'The first issue shows that at the beginning of the twentieth century there existed no more than 30 pure blooded animals scattered in small groups in several countries. The breeding centres which were a special concern of the Society existed in Britain, Germany, Holland, Sweden and Poland. The Polish breeding centre in Bialowieża had been restored in 1929 with two cows and one bull, all bought in Germany. 
During the next ten years, i.e., before the beginning of World War II, the number of European bison reached nearly a hundred. In 1938 there were 96, distributed as follows : Germany 35, Poland 30, Sweden 9, Britain 8, Holland 8. The remaining 6 animals were bulls exhibited in Zoos in various countries.

During World War II, when only the Swedish breeding centres of the European bison remained outside the war zone, the final destruction of the species seemed inevitable. Yet, strangely enough, this terrible six-years war did not affect greatly the bison population, except for the German breeding centre which suffered heavy losses.

The first post-war issue of the Pedigree Book published by the Polish section of the International Society for the Protection of the European Bison-the only section still functioning-states that the total number at 1st January, 1947, was 98, out of which 44 were in Poland, 20 in Germany, 4 in Holland, 16 in Sweden. The U.S.S.R. had joined the breeding countries and bought 6 animals from Poland.

The next three issues of the Pedigree Book, 1949, 1951 and 1953, showed a rise in the population of 22,23 and 41 respectively; the numbers in Poland being 57, 65 and 82. In 1953 the total bison population had reached 184.

Finally the last published issue of the Pedigree Book, 1st January, 1955, puts the total number of European bison at 213, an increase of 29 , but at the same time there is a sudden decrease of 11 in Poland, owing to the complete destruction of those in two reserves. This was by a violent attack of foot-andmouth disease, due to lack of adequate care and tardy realization of the discase's evil effects.

At the time of writing, the 1957 Pedigree Book has not yet been published, but information on the most important centres, except Germany, is available. So it can be stated with a high degree of accuracy that the total number of European bison on 1st January this year was about 250, of which 95 were in Poland.

On the basis of the above figures we can draw some general conclusions :-

(1) The example of the European bison indicates that it is not only with spear, bow and firearms that man harms animals ; the destruction of their environment is far more effective. It was of no avail to the European bison that it was the first animal to enjoy legal protection lasting twelve centuries.

(2) There is no reason to speak of the loss of vital powers or of the degeneration of the species. The fact of restoring of the 
Polish breeding centres, which started from three cows about thirty years ago and, in spite of the 1953 disaster, have now reached more than 100 head, indicates that there was no question of reduced fertility. Moreover, when making these calculations one should allow for the fact that a number of animals of Polish breeding were not counted in the total as they had been transferred to the newly organised breeding centres, e.g. in Bulgaria, U.S.S.R., Antwerp, Copenhagen, Prague, Rotterdam, and Vienna.

The causes of poor breeding of European bison in Białowieza Forest in Tsarist times have also been elucidated. It was extremely heavy competition by vast numbers of deer-red, roe and fallow-which were greatly encouraged on the official hunting grounds. Although haystacks were provided all through the winter for the bison, they were starved, especially in spring-time, not so much for want of sufficient quantity of food, but because of its bad quality. In the nineteenth century vitamins had not been discovered.

(3) The slightest neglect by man or relaxation of watchful care, even for a few months, over the European bison living in captivity, can bring about disastrous results even in the breeding centres of such long standing as the Polish ones-nearly forty animals lost during half a year.

(4) The figures recorded in the Pedigree books lead to yet another conclusion : the centres with large numbers of animals and a consistent breeding policy achieve far better results than small breeding centres, even of such a high standard as can be expected in zoological gardens.

\section{Conclusion}

If one considers that, by exercise of proper care, the numbers of the American bison were raised within thirty years from 500 to about 20,000 head, one may reasonably hope that his European relative, whose total number to-day is 250, can survive; and with progressive growth will reach a figure of over 1,000 head within the next ten years.

On the other hand, it has to be borne in mind that for the last 37 years the European bison has lived only in enclosures under conditions resembling those of domestic animals. If the bison is to be saved as a feature of the European landscape, it is essential that it should be let out into large open forests where it can take care of itself. Such an experiment was made in Poland in 1952-53, when two bulls, two cows and one calf were 
released in the open forest of Bialowieza. Since then they have managed well without extra food or special human attention. This justifies the hope that there is no question of any biological degeneration of the European bison and that it is well on the way to being saved as a wild animal. One might say that this species has been particularly lucky in having drawn upon itself the attention of man by rapidly dying out, just in time to make its rescue possible. 